\title{
SISTEM PENDUKUNG KEPUTUSAN PEMASARAN MOBIL DI TOYOTA AUTO2000 JEMBER DENGAN METODE FUZZY TOPSIS
}

\section{CAR MARKETING DECISION SUPPORT SYSTEM IN TOYOTA AUTO2000 JEMBER USING FUZZY TOPSIS METHOD}

\author{
Ari Susiana*, Ahmad Kamsyakawuni, Abduh Riski \\ Jurusan Matematika, Fakultas Matematika dan Ilmu Pengetahuan Alam, Universitas Jember \\ Jl. Kalimantan 37, Jember 68121 \\ *ariesusiana@gmail.com
}

\begin{abstract}
The number of car sales in Indonesia has increased over time. The dealer needs to determine the criteria of the car based on consumer needs as a marketing strategy so it can increase sales numbers. This research attempts to determine the best type of MPV (Multi Purpose Vehicle) car that is marketed at Toyota Auto2000 Jember dealers. The method used is fuzzy TOPSIS method with four criteria that are price, economical maintenance, comfort, and car models. The results obtained are ranking of the best MPV cars namely, Toyota Avanza, Innova, Sienta, Voxy, Alphard, and Vellfire.
\end{abstract}

\section{Keywords: Decision Support System, Marketing, Fuzzy TOPSIS.}

\begin{abstract}
ABSTRAK
Angka penjualan mobil di Indonesia mengalami peningkatan dari waktu ke waktu. Pihak dealer perlu menentukan kriteria mobil yang sesuai kebutuhan konsumen sebagai strategi pemasaran sehingga dapat meningkatkan angka penjualan. Penelitian ini dilakukan untuk menentukan tipe mobil MPV (Multi Purpose Vehicle) terbaik yang dipasarkan di dealer Toyota Auto2000 Jember. Metode yang digunakan yaitu metode fuzzy TOPSIS dengan empat kriteria yaitu harga, keekonomisan perawatan, kenyamanan, dan model mobil. Hasil yang didapatkan yaitu urutan peringkat tipe mobil MPV terbaik diantaranya, Toyota Avanza, Innova, Sienta, Voxy, Alphard, dan Vellfire.
\end{abstract}

\section{Kata kunci: Sistem Pendukung Keputusan, Pemasaran, Fuzzy TOPSIS.}

\section{PENDAHULUAN}

Berdasarkan data GAIKINDO, bulan Januari - Oktober 2019 penjualan mobil di Indonesia mencapai angka 849.609 unit. Toyota menduduki urutan pertama dalam penjualan dengan angka 275.374 unit dan persentase penyebaran 32.4\% (Gaikindo, 2019). Penyebaran dealer Toyota di Indonesia sangat luas, termasuk juga di wilayah Jember. Pihak dealer ketika akan melakukan pemasaran sering menjumpai kondisi dimana tidak dapat menentukan kriteria mobil secara tepat. Sehingga diperlukan adanya metode yang dapat mengatasi masalah pengambilan keputusan pemasaran. Metode yang dapat digunakan yaitu metode fuzzy TOPSIS (Technique For Order Preference By Similarity To 
Ideal Solution). Logika fuzzy digunakan karena memberi kemudahan perhitungan pengambilan keputusan yang menggunakan variabel linguistik (Rouhani et al., 2012). Metode TOPSIS digunakan dengan berbagai pilihan kriteria untuk memudahkan penentuan tipe mobil yang sesuai kebutuhan konsumen.

Pardede (2013) melakukan penelitian pemilihan sepeda motor menggunakan metode TOPSIS. Kriteria yang digunakan adalah harga, kapasitas mesin, pemakaian bahan bakar, kapasitas bagasi, dan warna. Pemberian kriteria dalam penelitiannya membantu pengambilan keputusan penentuan sepeda motor yang sesuai keinginan konsumen. Kemudian Sefrika (2018) melakukan penelitian menggunakan metode TOPSIS. Penelitiannya ditujukan untuk konsumen yang akan membeli mobil keluarga. Kriteria yang digunakan meliputi fitur, harga, kapasitas kendaraan dan kecepatan. Hasil penelitiannya menunjukkan bahwa konsumen lebih mempertimbangkan aspek harga sebelum menentukan pilihan ketika membeli mobil.

Penelitian ini membahas tentang penentuan pemasaran mobil MPV oleh pihak dealer Toyota Auto2000 Jember menggunakan metode fuzzy TOPSIS. Kriteria yang digunakan yaitu harga, keekonomisan perawatan, kenyamanan dan model mobil. Grafik fungsi keanggotaan disajikan menggunakan kurva segitiga.

\section{METODOLOGI}

Langkah pertama yaitu menentukan kriteria yang akan digunakan dengan wawancara dengan pihak dealer Toyota Auto2000. Langkah selanjutnya yaitu menentukan variabel linguistik dan nilai keanggotaan dari beberapa kriteria yang telah ditentukan. Variabel linguistik dan nilai keanggotaan kriteria ditunjukkan dengan Tabel 1 berikut ini.

Tabel 1 Variabel linguistik dan nilai keanggotaan kriteria

\begin{tabular}{ccccc}
\hline Harga & $\begin{array}{c}\text { Keekonomisan } \\
\text { Perawatan }\end{array}$ & Kenyamanan & Model & $\begin{array}{c}\text { Nilai } \\
\text { Keanggotaan }\end{array}$ \\
\hline Mahal & Kurang Ekonomis & Kurang Baik & Kurang Baik & $(0,0 ; 0,0 ; 0,3)$ \\
Sedang & Cukup & Cukup & Cukup & $(0,2 ; 0,5 ; 0,8)$ \\
Murah & Ekonomis & Baik & Baik & $(0,7 ; 1,0 ; 1,0)$ \\
\hline
\end{tabular}


Kemudian menentukan variabel linguistik dan nilai keanggotaan dari bobot setiap kriteria. Variabel linguistik dan nilai keanggotaan bobot kriteria ditunjukkan oleh Tabel 2 berikut ini.

Tabel 2 Variabel linguistik dan nilai keanggotaan bobot

\begin{tabular}{cc}
\hline Variabel Linguistik & Nilai Keanggotaan \\
\hline Tidak Penting & $(0,00 ; 0,00 ; 0,25)$ \\
Kurang Penting & $(0,00 ; 0,25 ; 0,50)$ \\
Cukup Penting & $(0,25 ; 0,50 ; 0,75)$ \\
Penting & $(0,50 ; 0,75 ; 1,00)$ \\
Sangat Penting & $(0,75 ; 1,00 ; 1,00)$
\end{tabular}

Grafik fungsi keanggotaan kriteria dan bobot disajikan menggunakan kurva segitiga seperti Gambar 1 dan Gambar 2 berturut-turut berikut ini.

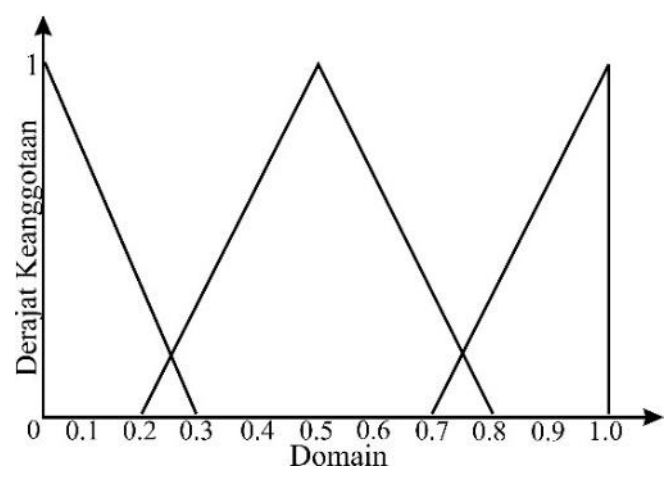

Gambar 1 Grafik fungsi keanggotaan kriteria

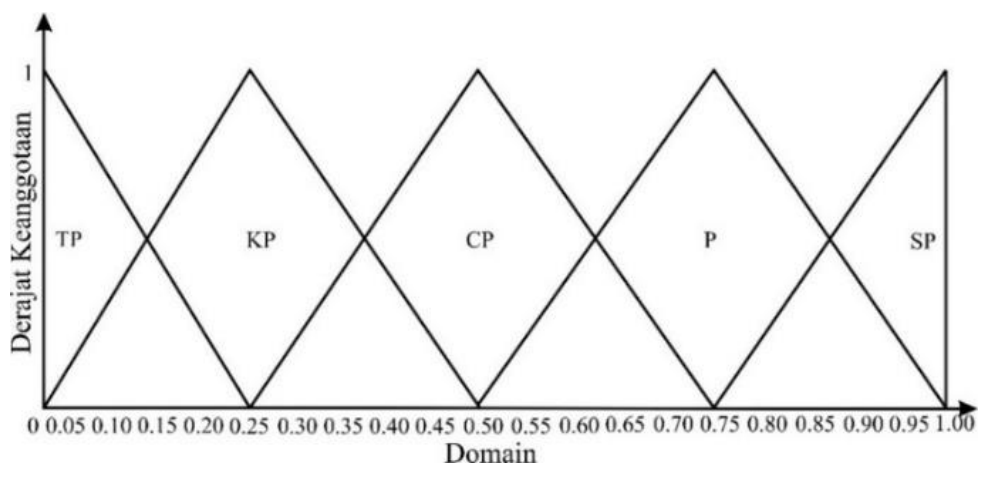

Gambar 2 Grafik fungsi keanggotaan bobot

Data penelitian dinilai oleh pegawai dealer Toyota Auto2000 sebagai pihak pemasaran dan ahli di bidang otomotif. Tipe mobil yang dinilai yaitu Toyota Avanza, Innova, Voxy, Alphard, Vellfire dan Sienta. Menurut Junior et al. (2014), tahapan metode fuzzy TOPSIS adalah sebagai berikut: 
1) Menetapkan matriks keputusan

Misalkan dalam pemilihan tipe mobil terdapat $m$ tipe mobil, $n$ kriteria dan $p$ penilai.

Nilai yang diberikan oleh penilai ke- $k$ untuk kriteria ke- $j$ dari tipe mobil ke- $i$ dinotasikan dengan $\tilde{x}_{i j}^{k}$ dimana $1 \leq i \leq m, 1 \leq j \leq n, 1 \leq k \leq p$. Sehingga dapat diperoleh matriks keputusan dari penilai ke- $k$, yaitu:

$$
\tilde{x}^{k}=\left[\begin{array}{cccc}
\tilde{x}_{11}^{k} & \tilde{x}_{12}^{k} & \cdots & \tilde{x}_{1 n}^{k} \\
\tilde{x}_{21}^{k} & \tilde{x}_{22}^{k} & \cdots & \tilde{x}_{2 n}^{k} \\
\vdots & \vdots & & \vdots \\
\tilde{x}_{m 1}^{k} & \tilde{x}_{m 2}^{k} & \cdots & \tilde{x}_{m n}^{k}
\end{array}\right] .
$$

Didefinisikan

$$
\tilde{x}_{i j}=\frac{1}{p}\left(\tilde{x}_{i j}^{1}+\tilde{x}_{i j}^{2}+\cdots+\tilde{x}_{i j}^{p}\right)
$$

sehingga dapat diperoleh matriks keputusan $\tilde{X}$

$$
\tilde{X}=\left[\begin{array}{cccc}
\tilde{x}_{11} & \tilde{x}_{12} & \cdots & \tilde{x}_{1 n} \\
\tilde{x}_{21} & \tilde{x}_{22} & \cdots & \tilde{x}_{2 n} \\
\vdots & \vdots & & \vdots \\
\tilde{x}_{m 1} & \tilde{x}_{m 2} & \cdots & \tilde{x}_{m n}
\end{array}\right] .
$$

2) Normalisasi matriks keputusan

Menormalisasikan matriks keputusan fuzzy $\tilde{X}$ menggunakan transformasi skala linier. Matriks keputusan fuzzy yang dinormalisasi $(\tilde{R})$ ditunjukkan oleh:

$$
\tilde{R}=\left[\tilde{r}_{i j}\right]_{m \times n}
$$

dengan

$$
\tilde{r}_{i j}=\left(\frac{a_{i j}}{c_{j}^{+}}, \frac{b_{i j}}{c_{j}^{+}}, \frac{c_{i j}}{c_{j}^{+}}\right)
$$

sehingga diperoleh matriks keputusan normal $\tilde{R}$ :

$$
\tilde{R}=\left[\begin{array}{cccc}
\tilde{r}_{11} & \tilde{r}_{12} & \cdots & \tilde{r}_{1 n} \\
\tilde{r}_{21} & \tilde{r}_{22} & \cdots & \tilde{r}_{2 n} \\
\vdots & \vdots & \ddots & \vdots \\
\tilde{r}_{m 1} & \tilde{r}_{m 2} & \cdots & \tilde{r}_{m n}
\end{array}\right] .
$$

3) Memberi bobot pada matriks keputusan normal

Jika $\widetilde{W}^{k}=\left[\begin{array}{llll}\widetilde{w}_{1}^{k} & \widetilde{w}_{2}^{k} & \cdots & \widetilde{w}_{n}^{k}\end{array}\right]^{\mathrm{T}}$ adalah vektor bobot $n$ kriteria yang diberikan oleh penilai ke- $k$, didefinisikan

$$
\widetilde{w}_{j}=\frac{1}{p}\left(\widetilde{w}_{j}^{1}+\widetilde{w}_{j}^{2}+\cdots+\widetilde{w}_{j}^{p}\right)
$$

maka dapat diperoleh vektor bobot dari kriteria, yaitu:

$$
\widetilde{W}=\left[\begin{array}{llll}
\widetilde{w}_{1} & \widetilde{w}_{2} & \cdots & \widetilde{w}_{n}
\end{array}\right]^{\mathrm{T}} .
$$

Kemudian didefinisikan 


$$
\tilde{V}=\widetilde{W} \times \tilde{R}
$$

sehingga dapat diperoleh matriks keputusan normal terboboti $\tilde{V}$.

$$
\tilde{V}=\left[\begin{array}{cccc}
\tilde{v}_{11} & \tilde{v}_{12} & \cdots & \tilde{v}_{1 n} \\
\tilde{v}_{21} & \tilde{v}_{22} & \cdots & \tilde{v}_{2 n} \\
\vdots & \vdots & \ddots & \vdots \\
\tilde{v}_{m 1} & \tilde{v}_{m 2} & \cdots & \tilde{v}_{m n}
\end{array}\right]
$$

4) Menentukan titik ideal terboboti

Titik ideal positif $A^{+}$dan titik ideal negatif $A^{-}$dari matriks keputusan normal terboboti $\tilde{V}$ adalah:

$$
\begin{aligned}
& A^{+}=\left[\begin{array}{llll}
\tilde{v}_{1}^{+} & \tilde{v}_{j}^{+} & \cdots & \tilde{v}_{m}^{+}
\end{array}\right]^{T} \\
& A^{-}=\left[\begin{array}{llll}
\tilde{v}_{1}^{-} & \tilde{v}_{j}^{-} & \cdots & \tilde{v}_{m}^{-}
\end{array}\right]^{T}
\end{aligned}
$$

dengan $\tilde{v}_{j}^{+}=(1,1,1)$ dan $\tilde{v}_{j}^{-}=(0,0,0)$.

5) Menghitung jarak alternatif

Jarak alternatif dihitung menggunakan definisi jarak euler. Jarak tipe mobil ke-i terhadap titik ideal positif terboboti ${\tilde{v}_{j}}^{+}$dan titik ideal negatif terboboti $\tilde{v}_{j}{ }^{-}$, didefinisikan sebagai $D_{i}^{+}$dan $D_{i}^{-}$.

$$
\begin{gathered}
d(\tilde{A}, \tilde{B})=\sqrt{\frac{1}{3}\left[\left(a_{1}-b_{1}\right)^{2}+\left(a_{2}-b_{2}\right)^{2}+\left(a_{3}-b_{3}\right)^{2}\right]} \\
D_{i}^{+}=\sum_{j=1}^{n} d\left(\tilde{v}_{i j}, \tilde{v}_{j}^{+}\right) \\
D_{i}^{-}=\sum_{j=1}^{n} d\left(\tilde{v}_{i j}, \tilde{v}_{j}^{-}\right)
\end{gathered}
$$

6) Menghitung derajat kedekatan

Kemudian dapat dihitung derajat kedekatan relatif tipe mobil ke- $i$ terhadap titik ideal positif.

$$
C C_{i}=\frac{D_{i}^{-}}{D_{i}^{+}+D_{i}^{-}}
$$

7) Memberi peringkat urutan pilihan

Masing-masing tipe mobil diberi peringkat berdasarkan derajat kedekatan $C C_{i}$. Tipe mobil dengan $C C_{i}$ terbesar akan diberi peringkat pertama, yang berarti paling direkomendasikan untuk dipasarkan di Toyota Auto2000 Jember. 


\section{PEMBAHASAN}

\subsection{Hasil}

Setelah dilakukan pengambilan data, didapatkan hasil penilaian oleh empat penilai dan data diubah menjadi bilangan fuzzy. Hal ini bertujuan untuk memudahkan perhitungan menggunakan variabel linguistik yang bersifat subjektif. Hasil perubahan data variabel linguistik oleh penilai menjadi bilangan fuzzy ditunjukkan oleh matriks $X_{i}$ di bawah ini.

$$
\begin{aligned}
& X_{1}=\left[\begin{array}{llll}
(0,2 ; 0,5 ; 0,8) & (0,2 ; 0,5 ; 0,8) & (0,7 ; 1,0 ; 1,0) & (0,2 ; 0,5 ; 0,8) \\
(0,2 ; 0,5 ; 0,8) & (0,2 ; 0,5 ; 0,8) & (0,7 ; 1,0 ; 1,0) & (0,7 ; 1,0 ; 1,0) \\
(0,0 ; 0,0 ; 0,3) & (0,2 ; 0,5 ; 0,8) & (0,7 ; 1,0 ; 1,0) & (0,7 ; 1,0 ; 1,0) \\
(0,0 ; 0,0 ; 0,3) & (0,0 ; 0,0 ; 0,3) & (0,7 ; 1,0 ; 1,0) & (0,7 ; 1,0 ; 1,0) \\
(0,0 ; 0,0 ; 0,3) & (0,0 ; 0,0 ; 0,3) & (0,7 ; 1,0 ; 1,0) & (0,7 ; 1,0 ; 1,0) \\
(0,2 ; 0,5 ; 0,8) & (0,2 ; 0,5 ; 0,8) & (0,7 ; 1,0 ; 1,0) & (0,2 ; 0,5 ; 0,8)
\end{array}\right] \\
& X_{2}=\left[\begin{array}{llll}
(0,2 ; 0,5 ; 0,8) & (0,7 ; 1,0 ; 1,0) & (0,7 ; 1,0 ; 1,0) & (0,7 ; 1,0 ; 1,0) \\
(0,0 ; 0,0 ; 0,3) & (0,2 ; 0,5 ; 0,8) & (0,7 ; 1,0 ; 1,0) & (0,7 ; 1,0 ; 1,0) \\
(0,0 ; 0,0 ; 0,3) & (0,2 ; 0,5 ; 0,8) & (0,7 ; 1,0 ; 1,0) & (0,7 ; 1,0 ; 1,0) \\
(0,0 ; 0,0 ; 0,3) & (0,0 ; 0,0 ; 0,3) & (0,7 ; 1,0 ; 1,0) & (0,7 ; 1,0 ; 1,0) \\
(0,0 ; 0,0 ; 0,3) & (0,0 ; 0,0 ; 0,3) & (0,7 ; 1,0 ; 1,0) & (0,7 ; 1,0 ; 1,0) \\
(0,2 ; 0,5 ; 0,8) & (0,2 ; 0,5 ; 0,8) & (0,7 ; 1,0 ; 1,0) & (0,7 ; 1,0 ; 1,0)
\end{array}\right] \\
& X_{3}= {\left[\begin{array}{lllll}
(0,2 ; 0,5 ; 0,8) & (0,2 ; 0,5 ; 0,8) & (0,7 ; 1,0 ; 1,0) & (0,7 ; 1,0 ; 1,0) \\
(0,2 ; 0,5 ; 0,8) & (0,2 ; 0,5 ; 0,8) & (0,7 ; 1,0 ; 1,0) & (0,7 ; 1,0 ; 1,0) \\
(0,0 ; 0,0 ; 0,3) & (0,2 ; 0,5 ; 0,8) & (0,7 ; 1,0 ; 1,0) & (0,7 ; 1,0 ; 1,0) \\
(0,0 ; 0,0 ; 0,3) & (0,0 ; 0,0 ; 0,3) & (0,7 ; 1,0 ; 1,0) & (0,7 ; 1,0 ; 1,0) \\
(0,0 ; 0,0 ; 0,3) & (0,0 ; 0,0 ; 0,3) & (0,7 ; 1,0 ; 1,0) & (0,7 ; 1,0 ; 1,0) \\
(0,7 ; 1,0 ; 1,0) & (0,7 ; 1,0 ; 1,0) & (0,2 ; 0,5 ; 0,8) & (0,2 ; 0,5 ; 0,8)
\end{array}\right] } \\
& X_{4}=\left[\begin{array}{llll}
(0,2 ; 0,5 ; 0,8) & (0,7 ; 1,0 ; 1,0) & (0,7 ; 1,0 ; 1,0) & (0,7 ; 1,0 ; 1,0) \\
(0,0 ; 0,0 ; 0,3) & (0,7 ; 1,0 ; 1,0) & (0,7 ; 1,0 ; 1,0) & (0,7 ; 1,0 ; 1,0) \\
(0,0 ; 0,0 ; 0,3) & (0,0 ; 0,0 ; 0,3) & (0,7 ; 1,0 ; 1,0) & (0,7 ; 1,0 ; 1,0) \\
(0,0 ; 0,0 ; 0,3) & (0,0 ; 0,0 ; 0,3) & (0,7 ; 1,0 ; 1,0) & (0,7 ; 1,0 ; 1,0) \\
(0,0 ; 0,0 ; 0,3) & (0,0 ; 0,0 ; 0,3) & (0,7 ; 1,0 ; 1,0) & (0,7 ; 1,0 ; 1,0) \\
(0,2 ; 0,5 ; 0,8) & (0,2 ; 0,5 ; 0,8) & (0,2 ; 0,5 ; 0,8) & (0,2 ; 0,5 ; 0,8)
\end{array}\right]
\end{aligned}
$$

Langkah selanjutnya membangun matriks keputusan berdasarkan matriks penilai di atas menggunakan persamaan 1 . Kemudian didapatkan nilai $\tilde{X}$ sebagai berikut:

$$
\tilde{X}=\left[\begin{array}{llll}
(0,20 ; 0,50 ; 0,80) & (0,45 ; 0,75 ; 0,90) & (0,70 ; 1,00 ; 1,00) & (0,57 ; 0,88 ; 0,95) \\
(0,10 ; 0,25 ; 0,55) & (0,33 ; 0,63 ; 0,85) & (0,70 ; 1,00 ; 1,00) & (0,70 ; 1,00 ; 1,00) \\
(0,00 ; 0,00 ; 0,30) & (0,15 ; 0,38 ; 0,68) & (0,70 ; 1,00 ; 1,00) & (0,70 ; 1,00 ; 1,00) \\
(0,00 ; 0,00 ; 0,30) & (0,00 ; 0,00 ; 0,30) & (0,70 ; 1,00 ; 1,00) & (0,70 ; 1,00 ; 1,00) \\
(0,00 ; 0,00 ; 0,30) & (0,00 ; 0,00 ; 0,30) & (0,70 ; 1,00 ; 1,00) & (0,70 ; 1,00 ; 1,00) \\
(0,33 ; 0,63 ; 0,85) & (0,33 ; 0,63 ; 0,85) & (0,45 ; 0,75 ; 0,90) & (0,33 ; 0,63 ; 0,85)
\end{array}\right]
$$

Setelah didapatkan matriks keputusan $\tilde{X}$, berikutnya menormalisasikan matriks keputusan menggunakan persamaan 2. Sehingga didapatkan nilai $\tilde{R}$ sebagai berikut: 


$$
\tilde{R}=\left[\begin{array}{llll}
(0,24 ; 0,59 ; 0,94) & (0,50 ; 0,83 ; 1,00) & (0,70 ; 1,00 ; 1,00) & (0,57 ; 0,88 ; 0,95) \\
(0,12 ; 0,29 ; 0,65) & (0,37 ; 0,70 ; 0,94) & (0,70 ; 1,00 ; 1,00) & (0,70 ; 1,00 ; 1,00) \\
(0,00 ; 0,00 ; 0,35) & (0,17 ; 0,42 ; 0,75) & (0,70 ; 1,00 ; 1,00) & (0,70 ; 1,00 ; 1,00) \\
(0,00 ; 0,00 ; 0,35) & (0,00 ; 0,00 ; 0,33) & (0,70 ; 1,00 ; 1,00) & (0,70 ; 1,00 ; 1,00) \\
(0,00 ; 0,00 ; 0,35) & (0,00 ; 0,00 ; 0,33) & (0,70 ; 1,00 ; 1,00) & (0,70 ; 1,00 ; 1,00) \\
(0,39 ; 0,74 ; 1,00) & (0,37 ; 0,70 ; 0,94) & (0,45 ; 0,75 ; 0,90) & (0,33 ; 0,63 ; 0,85)
\end{array}\right]
$$

Selain menilai beberapa tipe mobil berdasarkan kriteria, penilai juga memberi bobot untuk masing-masing kriteria. Kemudian penilaian bobot menggunakan variabel linguistik tersebut diubah menjadi bilangan fuzzy sehingga didapatkan vektor bobot sebagai berikut.

$$
\begin{array}{rlr}
w_{1}=\left[\begin{array}{l}
(0,75 ; 1,00 ; 1,00) \\
(0,75 ; 1,00 ; 1,00) \\
(0,50 ; 0,75 ; 1,00) \\
(0,50 ; 0,75 ; 1,00)
\end{array}\right] & w_{2}=\left[\begin{array}{l}
(0,75 ; 1,00 ; 1,00) \\
(0,75 ; 1,00 ; 1,00) \\
(0,75 ; 1,00 ; 1,00) \\
(0,75 ; 1,00 ; 1,00)
\end{array}\right] \\
w_{3}=\left[\begin{array}{l}
(0,75 ; 1,00 ; 1,00) \\
(0,75 ; 1,00 ; 1,00) \\
(0,75 ; 1,00 ; 1,00) \\
(0,75 ; 1,00 ; 1,00)
\end{array}\right] & w_{4}=\left[\begin{array}{l}
(0,75 ; 1,00 ; 1,00) \\
(0,75 ; 1,00 ; 1,00) \\
(0,75 ; 1,00 ; 1,00) \\
(0,75 ; 1,00 ; 1,00)
\end{array}\right]
\end{array}
$$

Selanjutnya menghitung rata-rata nilai bobot kriteria dari semua penilai menggunakan persamaan 3. Sehingga didapatkan nilai bobot $\widetilde{W}$ sebagai berikut:

$$
\widetilde{W}=\left[\begin{array}{l}
(0,75 ; 1,00 ; 1,00) \\
(0,75 ; 1,00 ; 1,00) \\
(0,69 ; 0,94 ; 1,00) \\
(0,69 ; 0,94 ; 1,00)
\end{array}\right]
$$

Kemudian menggunakan persamaan 4 akan diperoleh matriks keputusan normal terboboti $\tilde{V}$ seperti di bawah ini:

$$
\tilde{V}=\left[\begin{array}{llll}
(0,18 ; 0,59 ; 0,94) & (0,37 ; 0,83 ; 1,00) & (0,48 ; 0,94 ; 1,00) & (0,40 ; 0,83 ; 0,95) \\
(0,09 ; 0,29 ; 0,65) & (0,28 ; 0,70 ; 0,94) & (0,48 ; 0,94 ; 1,00) & (0,48 ; 0,94 ; 1,00) \\
(0,00 ; 0,00 ; 0,35) & (0,13 ; 0,42 ; 0,75) & (0,48 ; 0,94 ; 1,00) & (0,48 ; 0,94 ; 1,00) \\
(0,00 ; 0,00 ; 0,35) & (0,00 ; 0,00 ; 0,33) & (0,48 ; 0,94 ; 1,00) & (0,48 ; 0,94 ; 1,00) \\
(0,00 ; 0,00 ; 0,35) & (0,00 ; 0,00 ; 0,33) & (0,48 ; 0,94 ; 1,00) & (0,48 ; 0,94 ; 1,00) \\
(0,29 ; 0,74 ; 1,00) & (0,28 ; 0,70 ; 0,94) & (0,45 ; 0,75 ; 0,90) & (0,23 ; 0,59 ; 0,85)
\end{array}\right] .
$$

Guna mengetahui nilai titik ideal positif terboboti $\left(v^{+}\right)$dan titik ideal negatif terboboti $\left(v^{-}\right)$digunakan persamaaan 5 dan 6 . Kemudian didapatkan nilai $v^{+}$dan $v^{-}$sebagai berikut:

$$
v^{+}=\left[\begin{array}{c}
(1,00 ; 1,00 ; 1,00) \\
(1,00 ; 1,00 ; 1,00) \\
(1,00 ; 1,00 ; 1,00) \\
(1,00 ; 1,00 ; 1,00)
\end{array}\right] \quad v^{-}=\left[\begin{array}{l}
(0,00 ; 0,00 ; 0,00) \\
(0,00 ; 0,00 ; 0,00) \\
(0,00 ; 0,00 ; 0,00) \\
(0,00 ; 0,00 ; 0,00)
\end{array}\right] .
$$

Langkah selanjutnya yaitu menghitung jarak euler dengan persamaan 7. Kemudian dilanjutkan dengan menghitung jarak solusi ideal positif berdasarkan persamaan 8 dan 
solusi ideal negatif berdasarkan persamaan 9. Sehingga nilai $D^{+}$dan $D^{-}$diperoleh seperti yang tertera pada Tabel 3 berikut ini.

Tabel 3 Jarak solusi ideal positif dan solusi ideal negatif

\begin{tabular}{cc}
\hline$D^{+}$ & $D^{-}$ \\
\hline 1,5706 & 3,0310 \\
1,7524 & 2,7889 \\
2,1237 & 2,3828 \\
2,4065 & 2,0714 \\
2,4065 & 2,0714 \\
1,8354 & 2,7307
\end{tabular}

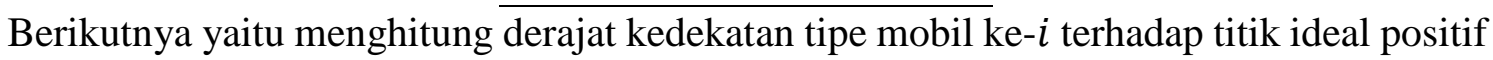
menggunakan persamaan 10. Setelah itu diperoleh hasil nilai derajat kedekatan $(C C i)$ seperti dalam Tabel 4 berikut.

Tabel 4 Nilai derajat kedekatan $(C C i)$

\begin{tabular}{ccc}
\hline Tipe mobil & $C C i$ & Urutan \\
\hline Avanza & 0,6587 & 1 \\
Innova & 0,6141 & 2 \\
Voxy & 0,5287 & 4 \\
Alphard & 0,4626 & 5 \\
Vellfire & 0,4626 & 6 \\
Sienta & 0,5980 & 3
\end{tabular}

Berdasarkan hasil nilai derajat keanggotaan di atas, langkah terakhir yaitu mengurutkan tipe mobil MPV sesuai nilai derajat keanggotaan terbesar. Urutan peringkat tipe mobil MPV terbaik ditunjukkan oleh Tabel 5 di bawah ini.

Tabel 5 Hasil urutan peringkat tipe mobil MPV

\begin{tabular}{cc}
\hline Peringkat & Tipe mobil \\
\hline 1 & Avanza \\
2 & Innova \\
3 & Sienta \\
4 & Voxy \\
5 & Alphard \\
6 & Vellfire \\
\hline
\end{tabular}




\subsection{Pembahasan}

Berdasarkan hasil perhitungan Toyota Avanza memiliki nilai derajat kedekatan terdekat dari solusi ideal positif. Semakin mendekati nilai 1, maka tipe mobil tersebut semakin banyak peminatnya di wilayah Jember. Toyota Voxy, Alphard dan Vellfire kurang unggul dari Toyota Avanza, Innova dan Sienta dari segi harga dan keekonomisan perawatan. Hal ini dikarenakan dari keempat kriteria yang digunakan, pihak dealer lebih mementingkan aspek harga dan keekonomisan perawatan untuk memasarkan tipe mobil. Hasil peringkat tipe mobil tersebut dapat digunakan pihak dealer untuk menyesuaikan kuantitas pemasaran tipe mobil di wilayah Jember. Selain itu tipe mobil di urutan teratas yaitu Avanza dapat ditampilkan pada display mobil di dealer Toyota Auto2000 Jember. Hal ini sebagai strategi pemasaran untuk penjualan mobil supaya dealer dapat memperoleh keuntungan.

Metode fuzzy TOPSIS dapat diterapkan pada sistem pendukung keputusan pemasaran mobil. Penerapan metode fuzzy TOPSIS menjadikan penilaian lebih efisien karena menggunakan bahasa sehari-hari. Metode fuzzy membuat pengambilan keputusan yang bersifat subjektif dapat menjadi lebih objektif. Hal ini dikarenakan metode fuzzy TOPSIS dapat digunakan untuk menghitung data yang menggunakan variabel linguistik.

\section{SIMPULAN}

Metode fuzzy TOPSIS dapat diterapkan dalam penentuan keputusan pemasaran mobil oleh pihak dealer Toyota Auto2000 Jember. Metode fuzzy membantu pengambilan keputusan yang bersifat subjektif menjadi lebih objektif. Berdasarkan keempat kriteria yang digunakan, pihak dealer lebih mementingkan aspek harga dan keekonomisan perawatan untuk pemasaran. Penelitian selanjutnya diharapkan dapat mengatasi masalah multikriteria menggunakan metode lainnya. Kriteria yang digunakan harus lebih spesifik misalnya dari segi warna dan jenis mobil matic atau manual. Selain itu penelitian selanjutnya juga dapat mengambil penilaian dari segi konsumen.

\section{DAFTAR PUSTAKA}

Gaikindo. 2019. Wholesales Jan-Okt 2019. https://www.gaikindo.or.id/indonesianautomobile-industry-data/ [Diakses pada 28 November 2019]. 
Junior, L.F.R., Osiro, L., dan Carpinetti, L.C.R. 2014. A Comparison between fuzzy AHP and fuzzy TOPSIS methods to supplier selection. Applied Soft Computing ASOC2238, 1-16.

Pardede, V. 2013. Sistem Pendukung Keputusan Pemilihan Kendaraan Bermotor Dengan Menggunakan Metode Technique For Order Preference By Similarity To Ideal Solution. Pelita Informatika Budi Darma. Vol IV No 1, 130-135.

Rouhani, S., Ghazanfari, M., dan Jafari, M. 2012. Evaluation Model Of Business Intelligence For Enterprise Systems Using Fuzzy Topsis. Expert Systems With Applications, 3764-3771.

Sefrika. 2018. Sistem Pendukung Keputusan Untuk Pemilihan Kendaraan Mobil Keluarga Dengan Metode Topsis. Jurnal Teknologi Informasi. Vol 10 No 2, 69-74. 